\title{
De-Regulation of Extracellular Matrix Proteins in Human Fibroblasts after Long-term and Low Concentrations of HEMA Exposition
}

\author{
Gabriella Teti ${ }^{1}$, Michela Zago ${ }^{2}$, Sandra Durante ${ }^{1}$, Stefano Focaroli ${ }^{1}$, Antonio Mazzotti ${ }^{3}$, Viviana Salvatore ${ }^{1}$, Matteo Cadossi ${ }^{3}$ and Mirella \\ Falconi* $^{1 *}$ \\ ${ }^{1}$ Department for Biomedical and Neuromotor Sciences (DIBINEM), University of Bologna, via Irnerio 48, Bologna, 40126 Italy \\ ${ }^{2}$ Meakins-Christie Laboratories, McGill University, 3626 St. Urbain Street, Montreal, Quebec H2X 2P2, Canada \\ ${ }^{3}$ Rizzoli Orthopedic Institute, Via di Barbiano 1/10, Bologna, 40136, Italy
}

\begin{abstract}
Background: 2 - hydroxyethyl methacrylate (HEMA) is one of the common components of most resin-based dental materials. Various studies have shown that HEMA can diffuse through dentin due to its low molecular weight and its hydrophilicity, and can affect the underlying odontoblast, cell division and activity. In this work, we have studied the influence of HEMA in regulating the expression of pro-collagen $\alpha 1$ type $I$ and tenascin - $C$ proteins in human fibroblasts after long term and low concentrations of HEMA.
\end{abstract}

Methods: Human dental pulp cells were exposed to $0.1 \mathrm{mM}$ and $0.5 \mathrm{mM}$ for $1,3,5,7$, and 15 days. MTT assay, immunofluorescence and western blot analysis were carried out to investigate cell viability and modification in collagen type I and tenascin - C protein expression.

Results: MTT assay showed an high cell viability, western blot and immunofluorescence demonstrated a down-regulation of collagen type I protein and un up-regulation of tenascin - C protein, the latter involved in cellular stress.

Conclusion: low concentrations and long-term HEMA exposition, greatly influences the expression of collagen type I protein and tenascin - $\mathrm{C}$ protein in human dental pulp cells, modifying the extracellular matrix toward a stressful microenvironment.

Keyword: Pulp fibroblasts; Extracellular matrix protein; Tenascin C; Pro-collagen al type I; HEMA

\section{Introduction}

The dental pulp is a specialized loose connective tissue composed of cells and extracellular matrix (ECM). The main cells type of dental pulp are the fibroblasts, responsible for the synthesis and secretion of the ECM [1]. ECM is not simply a scaffold, which would stabilize the physical structure of the tissue itself, but it also has an important role in the adhesion, mobility, spreading, proliferation, and differentiation of the pulpal cell population [2-4]. ECM of pulp tissue comprises a variety of proteins and polysaccharides that are secreted locally, forming a neat network. Matrix macromolecules include collagenous proteins like type I (col I), III and IV collagens, noncollagenous proteins such as fibronectin (FN), tenascin - C (TNC), osteonectin (ONEC), osteopontin and osteocalcin, proteoglycans, and phospholipids [5].

Tenascin - C is a large oligomeric ECM glycoprotein selectively expressed in a variety of connective tissues during embryogenesis [6]. This property, coupled with the effects of TNC on cellular behavior, suggests that TNC-containing extracellular matrices might help to orchestrate development by determining whether cells adhere to a substratum, to each other, or by providing a provisional matrix that is conducive for cellular migration, division, differentiation or apoptosis [7]. In normal adult tissue, this protein becomes confined into tissues submitted to mechanical loads, such as pericondrium, periostium, ligaments, tendons, myotendinous junctions and smooth muscle, in which its expression is less abundant [8]. It is also found in malignant epithelial and mesenchymal tumors and healing wounds. Moreover, TNC is highly expressed during development and under pathological conditions caused by infections and inflammations and mechanical stress applied either to cells in culture or to tissue $[9,10]$.

Dental pulp is involved in damage induced by dental restorative materials in which monomers released from the polymerized resin matrix can reach the dental pulp through dentin tubules, causing adverse effects such as tissue inflammation [11,12] apoptosis [13], genotoxic and mutagenic effects [14], reduction of cell proliferation [15] and alteration of the expression of collagen type I [16-18] and TNC proteins.

2 - hydroxyethyl methacrylate (HEMA) is one of the common components of most resin-based dental materials used in amounts comprised between $35-50 \%[19,20]$ in order to reduce viscosity [20], to prevent collagen collapse [21,22] and to increase bond strengths [23]. Various studies have shown that HEMA can diffuse through dentin due to its low molecular weight [24] and its hydrophilicity, and can affect the underlying odontoblast, cell division and activity [12].

The aim of this study was to test the effect of low concentrations of HEMA for long term exposition in human dental pulp fibroblasts (HPFs), evaluating the expression of collagen type I protein and TNC after the treatment. The final goal is to in vitro simulate a low but

*Corresponding author: Mirella Falconi, Department of Biomedical and Neuromotor Sciences (DIBINEM), University of Bologna, via Irnerio, 48 40126 Bologna, Italy, Tel: +39 051 2091511; Fax: +39 051 251735; E-mail: mirella.falconi@unibo.it

Received February 26, 2014; Accepted March 25, 2014; Published March 27 , 2014

Citation: Teti G, Zago M, Durante S, Focaroli S, Mazzotti A, et al. (2014) DeRegulation of Extracellular Matrix Proteins in Human Fibroblasts after Longterm and Low Concentrations of HEMA Exposition. J Cytol Histol 5: 235. doi:10.4172/2157-7099.1000235

Copyright: ( 2014 Teti G, et al. This is an open-access article distributed under the terms of the Creative Commons Attribution License, which permits unrestricted use, distribution, and reproduction in any medium, provided the original author and source are credited. 
constant exposition of pulp cells to resin monomers released from polymerized matrix at low concentrations.

The influence of HEMA on HPFs viability was evaluated by MTT assay, while immunofluorescence and western blotting analyses were carried out to detect the expression of pro-collagen al type I and TNC proteins after HEMA exposition.

\section{Materials and Methods}

\section{Primary culture HPFs}

HPFs were isolated from the third molars of healthy normal volunteers during routine oral surgery. Informed consent was obtained from the donors. The central part of the dental papilla was cut into small pieces, washed with phosphate buffered saline (PBS) and incubated in Dulbecco's Modified Essential Medium (DMEM/ F12), containing $10 \%$ fetal bovine serum (FBS) and $1 \%$ penicillin and streptomycin. Monolayer cultures were maintained at $37^{\circ} \mathrm{C}$ in a humidified atmosphere of $5 \%(\mathrm{v} / \mathrm{v}) \mathrm{CO}_{2}$.

\section{HEMA treatment}

A stock solution of 2M HEMA was dissolved in ethanol. Subsequently, $0.1 \mathrm{mM}$ and $0.5 \mathrm{mM}$ HEMA solutions in DMEM supplemented with $2 \%$ of FBS were prepared.

HPFs were exposed to $0.1 \mathrm{mM}$ and $0.5 \mathrm{mM}$ for different period of time ranging from 1 day, 3 days, 5 days, 7 days and 15 days.

\section{MTT assay}

HPFs were seeded at concentration of $1 \times 10^{4}$ into a 96-well culture plate. After $24 \mathrm{~h}$, the medium was changed to a fresh one containing $0.1 \mathrm{mM}$ or $0.5 \mathrm{mM}$ HEMA. All samples were left for 15 days, refreshing the medium every day during this time of exposition. At the end of the treatment, cells were washed with PBS and the medium was changed to a new one containing $0.5 \mathrm{mg} / \mathrm{ml}$ of 3-(4,5-dimethylthiazol-2-yl)2,5-diphenyltetrazolium bromide (MTT) and left for $2 \mathrm{~h}$ at $37^{\circ} \mathrm{C}$. The formazan produced was dissolved by solvent solution $(0,1 \mathrm{~N} \mathrm{HCl}$ in isopropanol) and the optical density was read at $570 \mathrm{~nm}$ by Microplate Reader (Model 680, Biorad Lab Inc., CA, USA).

\section{Double-Immunofluorescence analysis for pro-collagen al type $I$ and tenascin $C$ proteins}

HPFs were grown in monolayers on cover glasses and treated with $0.1 \mathrm{mM}$ and $0.5 \mathrm{mM}$ HEMA for 2 weeks. Two cover glasses were prepared for each treatment and the entire experiment was performed three times. Samples were washed rapidly in PBS and fixed with $4 \%$ formalin/ $0.1 \%$ Triton X-100 in PBS for $20 \mathrm{~min}$ at $4^{\circ} \mathrm{C}$. After washes in PBS samples were blocked in $1 \%$ dry milk (blocking reagent) (Bebilac, Sicura, France) in PBS for $90 \mathrm{~min}$ at room temperature (RT). The cover glasses were then incubated with anti-human pro-collagen al type I antibody (Santa Cruz Biotechnology, Inc., Santa Cruz, CA, USA) diluted 1:400 and anti-human tenascin - C antibody (Sigma Aldrich, Saint Louis, Missouri, USA) diluted 1:100 both in blocking reagent for $1 \mathrm{~h}$ at $37^{\circ} \mathrm{C}$. After washes in PBS, samples were incubated respectively with CY3-conjugated anti-goat IgG antibody (Sigma Aldrich, Saint Louis, Missouri, USA) diluted 1:2000 and FITCH- conjugated antimouse IgG antibody (Sigma Aldrich, Saint Louis, Missouri, USA) diluted 1:100, always in blocking reagent. Finally, the slides were washed three times in PBS and then mounted in VECTASHIELD mounting medium with 4', 6-diamidino-2-phenylindole (DAPI) (Vector Laboratories, Burlingame, CA, USA). The slides were observed by a fluorescence microscope (Nikon Eclipse E800, Tokyo, Japan).

\section{Protein extraction and SDS-PAGE and Western Blotting}

At the end of HEMA treatment, cytosolic extracts were prepared by RIPA modified lysis buffer (50 mM Tris- $\mathrm{HCl}$ pH 7.4; 1\% NP-40; 150 mM NaCl; 2 mM EDTA; 0.1\% SDS; 1 mM EGTA; 1 mM PMSF; 0.15\% $\beta \mathrm{ME}$ ) supplemented with a $25 \mu \mathrm{M}$ protease inhibitor cocktail (Sigma Aldrich, St. Luis, Missouri, USA). A Bradford protein assay [25] was performed to quantify the amount of proteins obtained in each sample.

$50 \mu \mathrm{g}$ of total proteins extracted from each sample were resolved on $8 \%$ SDS polyacrylamide gel electrophoresis (SDS-PAGE) and then electrophoretically transferred into a nitrocellulose membrane using a wet blotting apparatus (Mini Tank Electroblotting System, Owl, Portsmouth, UK). The membranes were blocked with $2.5 \%$ dry milk (Bebilac, Sicura, France) in TBS-Tween buffer, $\mathrm{pH} 7.5$ for $2 \mathrm{~h}$ at $37^{\circ} \mathrm{C}$ and then incubated with primary antibodies: anti-human pro-collagen a1 type I (Santa Cruz Biotechnology, INC., Santa Cruz, CA, USA) diluted 1:5000, anti- $\beta$ tubulin (Sigma Aldrich, Saint Luis, Missouri, USA) diluted 1:10000 and anti-human tenascin-C (Sigma Aldrich, Saint Luis, Missouri, USA) diluted 1:250, all in dry milk. After several washes in TBS-Tween buffer, the membranes were incubated with the specific HRP (horseradish peroxidase) conjugated antibody. For procollagen $\alpha 1$ type I protein and $\beta$ tubulin protein, the secondary HRP conjugated antibody was diluted 1:80000 (Santa Cruz Biotechnology, INC., Santa Cruz, CA, USA) for $2 \mathrm{~h}$ at $37^{\circ} \mathrm{C}$, while for tenascin-C protein, the secondary antibody was diluted 1:50000 (Sigma Aldrich, Saint Luis, Missouri, USA) for the same time and temperature.

The detection system was the enhancement chemiluminescence system LiteAblot ${ }^{\oplus}$ (Euroclone SA, Lugano, Switzerland). Images were obtained by Image Station 2000R (Kodak, NY, USA).

\section{Controls}

HPFs treated with $0.3 \%$ of ethanol were utilized as control, to assay the influence of the solvent on cell expression and synthesis of procollagen $\alpha 1$ type I and tenascin-C proteins. For immunofluorescence labelling, the control specimens consisted in HPFs fixed with $4 \%$ formalin/ $0.1 \%$ Triton X-100 and incubated only with the specific secondary antibody CY3-conjugated to check the presence of a nonspecific interaction between the antibody and the free aldehyde groups of the fixative.

\section{Results}

\section{MTT assay}

MTT assay showed high levels of cell viability in HPFs exposed to both $0.1 \mathrm{mM}$ and $0.5 \mathrm{mM}$ for 15 days (Figure 1), suggesting that the HEMA concentrations tested were not cytotoxic after a long term exposition.

\section{Double-immunofluorescence for pro-collagen $\alpha 1$ type I and tenascin- $C$}

To verify the potential effect of HEMA on the production of extracellular matrix proteins, a double-immunofluorescence for procollagen al type I and TNC proteins was carried out on HPFs in vitro cultured and exposed to HEMA for 15 days.

Figures $2 \mathrm{~A}$ and $2 \mathrm{~B}$ show HPFs without any HEMA treatment. Procollagen $\alpha 1$ type I protein appeared organized in small clusters around the cell nucleus, while a faint signal corresponding to TNC protein was detected. 


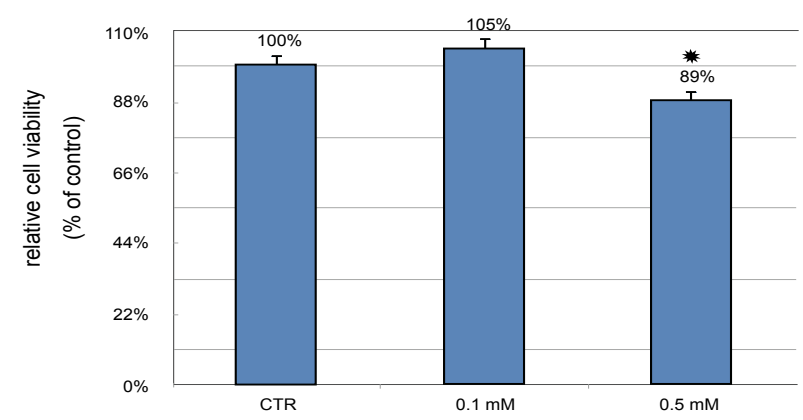

HEMA concentrations

Figure 1: Cell viability of HPFs exposed to $0.1 \mathrm{mM}$ and $0.5 \mathrm{mM}$ HEMA for 15 days. Values of cell viability about $100 \%$ were observed in both specimens treated. Samples exposed to $0.1 \mathrm{mM}$ and to $0.5 \mathrm{mM}$ show cell viability respectively of $105 \%$ and $89 \%$. The data represent the mean ( \pm S.D.) of triplicate experiments per condition and are expressed as a percentage of the control value. The MTT data were statistically analyzed by one-way ANOVA followed by Dunnet test. $\left(^{*}\right)$ statistically significant differences between groups $(p<0.05)$.

Figure $2 \mathrm{C}$ showed a still high signal of the protein pro-collagen $\alpha 1$ type I in samples treated with $0.1 \mathrm{mM}$ of HEMA, while the signal was almost absent in cells treated with $0.5 \mathrm{mM}$ of HEMA (Figure 2D). On the contrary, TNC protein showed a low signal in samples treated with $0.1 \mathrm{mM}$ of HEMA, and a very high signal in samples treated with 0.5 mM of HEMA.

\section{Western Blot for pro-collagen al type I and tenascin-C}

To confirm the results obtained by immunofluorescence, western blot analysis was carried in samples treated with HEMA for 15 days. Procollagen a1 type I protein showed an high signal in HPFs exposed to $0.1 \mathrm{mM}$ of HEMA while a reduced protein signal is observed in samples treated with $0.5 \mathrm{mM}$ (Figure $3 \mathrm{~A}$ ).

TNC protein showed an opposite trend, a low signal in control and $0.1 \mathrm{mM}$ treated samples, while an up-regulation of the protein is detected in HPFs exposed to $0.5 \mathrm{mM}$ of HEMA for 15 days (Figure 3B).

To better investigate the upregulation of Tenascin - C protein in treated samples, some HPFs were tested for short term HEMA exposition. Results showed a gradual up-regulation of the protein in samples exposed to $0.1 \mathrm{mM}$ HEMA, while the signal was always high in samples treated for 1, 3, 5 and 7 days with $0.5 \mathrm{mM}$ of HEMA (Figure 4).

\section{Discussion}

HEMA is one of the main components in dental restorative materials, but it is widely utilized in other fields such as ophthalmology for production of contact lenses [26,27], in drug delivery and in tissue engineering [28]. Several studies demonstrated that HEMA monomers are rapidly released from the polymerized matrix [29], reach dental pulp and induce adverse effects [30,31].

The toxicity and genotoxicity of HEMA has been widely studied [14], but the adaptive mechanisms involved in cell responses towards stress induced by methacrylate materials are still under discussion [32].

Our group had previously demonstrated the interference of high concentrations of HEMA for short term exposition on the production of collagen type I protein and TNC protein in human gingival fibroblasts and dental pulp cells [16-18], but the effects of low concentrations of resin dental monomers for long term exposition are still poor investigated. It was reported that eluates of resin monomers in the micromolar range are still detectable after 30 days from polymerization of dental material [33].

The aim of this study was to test low concentrations of HEMA for long term exposition in human dental pulp fibroblasts, evaluating the expression of collagen type I protein and TNC after the treatment. The final goal is to in vitro simulate a low but constant exposition of pulp cells to resin monomers released from polymerized matrix at low concentrations.

MTT results showed that HPFs viability is high in samples exposed
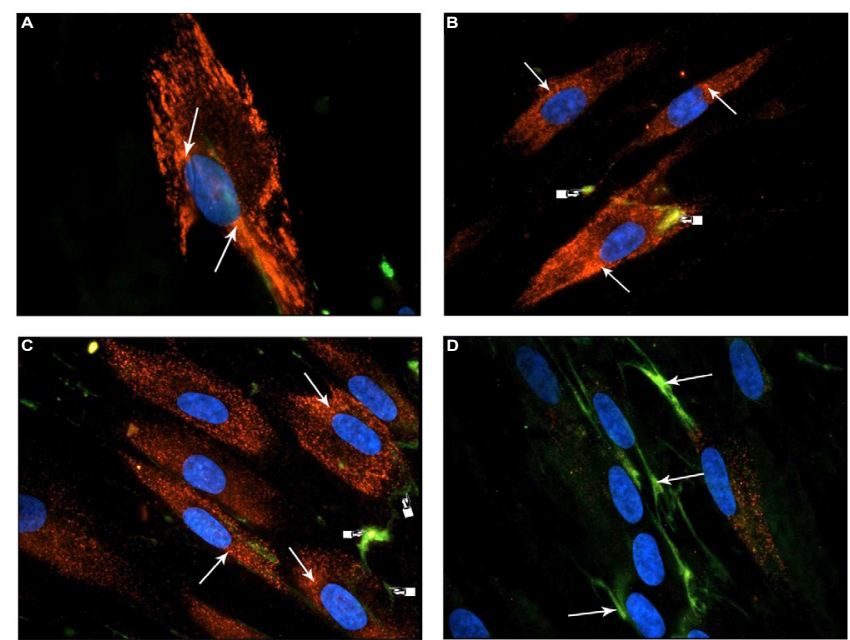

Figure 2: Immunocytochemical localization of pro-collagen a1 type I and tenascin $\mathrm{C}$ proteins in HPFs treated with $0.1 \mathrm{mM}$ and $0.5 \mathrm{mM}$ HEMA for 15 days. CY3-conjugated anti-goat and FITCH-conjugated anti-mouse both IgG antibody were used to detect the double-localization of the proteins. All samples were counterstained with DAPI. (A) and (B) show HPFs without any treatment. Red signal correspond to $\mathrm{CY} 3$ pro-collagen a1 type I protein (arrow). FITC fluorescent signal (green) corresponds to tenascin-C protein; (C) Samples exposed to $0.1 \mathrm{mM}$ HEMA showed pro-collagen $\alpha 1$ type I protein (arrow). (D) Samples treated with $0.5 \mathrm{mM}$ of HEMAs showed an high signal of TNC (arrow). All the images were 600X.

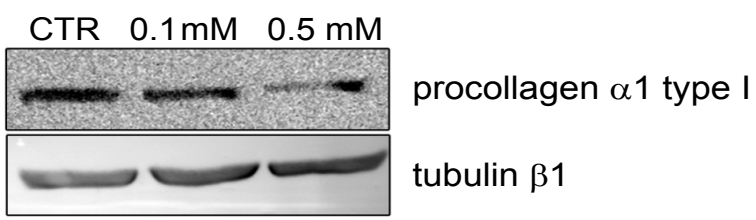

A

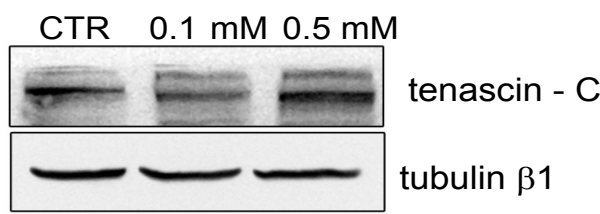

\section{B}

Figure 3: Western blot analysis for pro-collagen a1 type I (A) and tenascin $C$ (B) proteins in HPFs exposed to $0.1 \mathrm{mM}$ and $0.5 \mathrm{mM}$ HEMA for 15 days. 


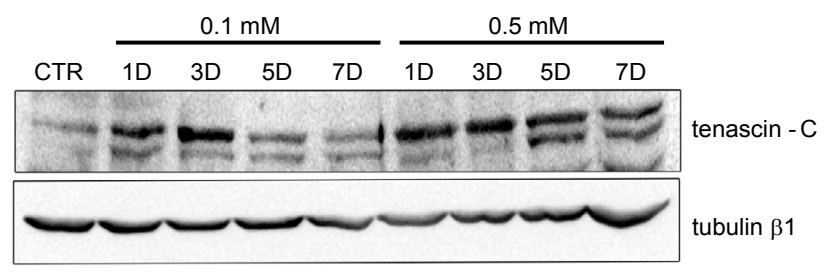

Figure 4: Western blot analysis for tenascin $C$ proteins in HPFs exposed to 0.1 $\mathrm{mM}$ and $0.5 \mathrm{mM}$ HEMA for $151,3,5$ and 7 days.

both to $0.1 \mathrm{mM}$ and $0.5 \mathrm{mM}$ HEMA. Samples treated with $0.1 \mathrm{mM}$ HEMA demonstrated a cell viability comparable to control sample, while cell viability in samples exposed to 0.5 mM HEMA was of $89 \%$. These data demonstrate that the concentrations tested of HEMA for 15 days are highly biocompatible and that cells did not show any serious damage.

Immunofluorescence data and western blot analysis demonstrated different results. Both techniques confirm that low concentrations of HEMA and long term exposition were responsible of a down-regulation of the protein pro-collagen type I and an up-regulation of TNC protein. In particular, TNC showed a low reduction in samples treated for 7 days with $0.1 \mathrm{mM}$ HEMA followed by an up-regulation of the protein in cells treated with $0.5 \mathrm{mM}$ of HEMA. These data immediately suggest that although cell viability is high after resin monomer exposition, HPFs show early signs of cellular stress undetected by cell viability assay.

In adult tissues, both proteins are widely expressed in tissues submitted to mechanical loads, such as pericondrium, periostium, ligaments, tendons, myotendinous junctions [8]. TNC is also found in malignant epithelial, mesenchymal tumors, healing wounds and under pathological conditions caused by infections and inflammations $[9,10]$.

Our results demonstrated that, even in apparently high viability conditions, HPFs exposed to HEMA showed adaptive mechanisms towards cellular stress. The down-regulation of collagen type I in combination with an up-regulation of TNC protein, suggested a deep modification of extracellular matrix tissue with changes in its mechanical strength. As consequence, a loose interaction of dental materials with dentin structure is supposed .

The high expression of TNC, generally associated in adult tissues to pathological conditions, could be utilized as a biomarker of cellular stress induced by resin monomer.

\section{Acknowledgment}

This study was supported by Italian Ministry of Research and Technology (MURST) with an FIRB grant (RBAP10MLK7_005) and Fondazione del Monte di Bologna and Ravenna 2012 grant.

\section{References}

1. Goldberg M, Lasfargues JJ (1995) Pulpo-dentinal complex revisited. J Dent 23: $15-20$.

2. Lukinmaa PL, Mackie EJ, Thesleff I (1991) Immunohistochemical localization of the matrix glycoproteins--tenascin and the ED-sequence-containing form of cellular fibronectin--in human permanent teeth and periodontal ligament. J Dent Res 70: 19-26.

3. Lesot H, Osman M, Ruch JV (1981) Immunofluorescent localization of collagens, fibronectin, and laminin during terminal differentiation of odontoblasts. Dev Biol 82: $371-381$.
4. Nakashima M, Akamine A (2005) The application of tissue engineering to regeneration of pulp and dentin in endodontics. J Endod 31: 711-718.

5. Goldberg M, Smith AJ (2004) Cells And Extracellular Matrices Of Dentin And Pulp: A Biological Basis For Repair And Tissue Engineering. Crit Rev Oral Bio Med 15: 13-27.

6. Sahlberg C, Aukhil I, Thesleff I (2001) Tenascin-C in developing mouse teeth expression of splice variants and stimulation by TGFbeta and FGF. Eur J Oral Sci 109: 114-124.

7. Jones PL, Jones FS (2000) Tenascin-C in development and disease: gene regulation and cell function. Matrix Biol 19: 581-596.

8. Jallo GI, Friedlander DR, Kelly PJ, Wisoff JH, Grumet M, et al. (1997) Tenascin-C expression in the cyst wall and fluid of human brain tumors correlates with angiogenesis. Neurosurgery 41: 1052-1059.

9. Chiquet-Ehrismann R, Chiquet M (2003) Tenascins: regulation and putative functions during pathological stress. J Pathol 200: 488-499.

10. Chiquet-Ehrismann R, Tannheimer M, Koch M, Brunner A, Spring J, et al. (1994) Tenascin-C expression by fibroblasts is elevated in stressed collagen gels. J Cell Biol 127: 2093-2101.

11. Stanley HR (1992) Biological evaluation of dental materials. Int Dent J 42: 37-46.

12. Bouillaguet S, Wataha JC, Hanks CT, Ciucchi B, Holz J (1996) In vitro cytotoxicity and dentin permeability of HEMA. J Endod 22: 244-248.

13. Spagnuolo G, Galler K, Schmalz G, Cosentino C, Rengo S, et al. (2004) Inhibition of phosphatidylinositol 3-kinase amplifies TEGDMA-induced apoptosis in primary human pulp cells. J Dent Res 83: 703-707.

14. Schweikl H, Spagnuolo G, Schmalz G (2006) Genetic and cellular toxicology of dental resin monomers. J Dent Res 85: 870-877.

15. Samuelsen JT, Holme JA, Becher R, Karlsson S, Morisbak E, et al. (2008) HEMA reduces cell proliferation and induces apoptosis in vitro. Dent Mater 24 134-140.

16. Falconi M, Teti G, Zago M, Pelotti S, Breschi L, et al. (2007) Effects of HEMA on type I collagen protein in human gingival fibroblasts. Cell Biol Toxicol 23 313-322.

17. Teti G, Mazzotti G, Zago M, Ortolani M, Breschi L, et al. (2009) HEMA downregulates procollagen alpha1 type I in human gingival fibroblasts. J Biomed Mater Res A 90: 256-262.

18. Zago M, Teti G, Mazzotti G, Ruggeri A, Breschi L, et al. (2008) Expression of procollagen alpha1 type I and tenascin proteins induced by HEMA in human pulp fibroblasts. Toxicol In Vitro 22: 1153-1159.

19. Pashley EL, Zhang Y, Lockwood PE, Rueggeberg FA, Pashley DH (1998) Effects of HEMA on water evaporation from water-HEMA mixtures. Dent Mater 14: 6-10.

20. Nakabayashi N, Takarada K (1992) Effect of HEMA on bonding to dentin. Dent Mater 8: 125-130.

21. Carvalho RM, Yoshiyama M, Pashley EL, Pashley DH (1996) In vitro study on the dimensional changes of human dentine after demineralization. Arch Oral Biol 41: 369-377.

22. Hitmi L, Bouter D, Degrange M (2002) Influence of drying and HEMA treatment on dentin wettability. Dent Mater 18: 503-511.

23. Munksgaard EC, Asmussen E (1984) Bond strength between dentin and restorative resins mediated by mixtures of HEMA and glutaraldehyde. J Dent Res 63: 1087-1089.

24. Hamid A, Hume WR (1997) Diffusion of resin monomers through human carious dentin in vitro. Endod Dent Traumatol 13: 1-5.

25. Bradford MM (1976) A rapid and sensitive method for the quantitation of microgram quantities of protein utilizing the principle of protein-dye binding Anal Biochem 72: 248-254

26. Goda T, Ishihara K (2006) Soft contact lens biomaterials from bioinspired phospholipid polymers. Expert Rev Med Devices 3: 167-174.

27. Lord MS, Stenzel MH, Simmons A, Milthorpe BK (2006) The effect of charged groups on protein interactions with poly(HEMA) hydrogels. Biomaterials 27 : 567-575.

28. Mei N, Chen G, Zhou P, Chen X, Shao ZZ, et al. (2005) Biocompatibility of 
Citation: Teti G, Zago M, Durante S, Focaroli S, Mazzotti A, et al. (2014) De-Regulation of Extracellular Matrix Proteins in Human Fibroblasts after Long-term and Low Concentrations of HEMA Exposition. J Cytol Histol 5: 235. doi:10.4172/2157-7099.1000235

Page 5 of 5

Poly(epsilon-caprolactone) scaffold modified by chitosan--the fibroblasts proliferation in vitro. J Biomater Appl 19: 323-339.

29. Cetingüç A, Olmez S, Vural N (2007) HEMA diffusion from dentin bonding agents in young and old primary molars in vitro. Dent Mater 23: 302-307.

30. Nocca G, De Palma F, Minucci A, De Sole P, Martorana GE, et al. (2007) Alterations of energy metabolism and glutathione levels of HL-60 cells induced by methacrylates present in composite resins. J Dent 35: 187-194

31. Chang HH, Guo MK, Kasten FH, Chang MC, Huang GF, et al. (2005) Stimulation of glutathione depletion, ROS production and cell cycle arrest of dental pulp cells and gingival epithelial cells by HEMA. Biomaterials 26: 745-753.

32. Krifka S, Spagnuolo G, Schmalz G, Schweikl H (2013) A review of adaptive mechanisms in cell responses towards oxidative stress caused by dental resin monomers. Biomaterials 34: 4555-4563.

33. Van Landuyt KL, Nawrot T, Geebelen B, De Munck J, Snauwaert J, et al (2011) How much do resin-based dental materials release? A meta-analytical approach. Dent Mater 27: 723-747. 